\title{
On the Synchronizing Mechanisms of Tetanically Induced Hippocampal Oscillations
}

\author{
Enrico Bracci, Martin Vreugdenhil, Stephen P. Hack, and John G. R. Jefferys \\ Department of Neurophysiology, Division of Neuroscience, The Medical School, The University of Birmingham, \\ Birmingham B15 2TT, United Kingdom
}

$\gamma(30-100 \mathrm{~Hz})$ and $\beta(10-30 \mathrm{~Hz})$ oscillations follow tetanic stimulation in the CA1 region of the rat hippocampal slice. Pyramidal neurons undergo a slow depolarization after the tetanus and generate synchronous action potentials. The slow depolarization was previously attributed to metabotropic glutamate receptor (mGluR) activation. However, we found that this event was mediated by $\mathrm{GABA}_{\mathrm{A}}$ receptors, being blocked by bicuculline $(50 \mu \mathrm{M})$ and accompanied by a dramatic drop in input resistance. Experiments with NMDA and non-NMDA glutamate receptor antagonists revealed that fast synaptic excitation was not necessary for oscillations. IPSPs were strongly depressed during the oscillations. Instead, synchronization was caused by field effects, as shown by: (1) Action potentials of pyramidal neurons proximal $(<200 \mu \mathrm{m})$ to the stimulation site were often preceded by negative deflections of the intracellular potential that masked a net transmembrane depolarization

Coherent cortical oscillations at $\gamma(30-100 \mathrm{~Hz})$ and $\beta(10-30 \mathrm{~Hz})$ frequencies are implicated in a range of behaviors, including cognitive tasks such as object recognition (Singer and Gray, 1995). Several in vitro models for $\gamma$ oscillations have been developed recently, and provide detailed insights into the properties of the neuronal networks responsible (Whittington et al., 1995, 1997a,b; Traub et al., 1996b; Buhl et al., 1998; Fisahn et al., 1998). In the CA1 region of the hippocampal slice, $\gamma$ oscillations can be elicited by focal application of glutamate (Whittington et al., 1995; Traub et al., 1996a) and by tetanic stimulation (Traub et al., 1996b; Whittington et al., 1997a); here we will term this latter form "post-tetanic $\gamma$ ".

Glutamate-induced $\gamma$ depends on mutual inhibition between interneurons that are tonically excited by metabotropic glutamate receptor (mGluR) activation (Whittington et al., 1995; Traub et al., 1996a). Pyramidal cells normally do not fire during this form of $\gamma$, but they do experience rhythmic IPSPs that provide a timing signal that can determine when a pyramidal cell will fire if it is brought to threshold by other inputs (Buzsáki and Chrobak, 1995; Burchell et al., 1998). Post-tetanic $\gamma$ differs from glutamateinduced $\gamma$ in the massive, synchronous firing activity of the principal neurons (Traub et al., 1996b; Whittington et al., 1997a). It is driven by a slow depolarization that develops after the end of the tetanus (Whittington et al., 1997a). In a series of studies,

Received May 6, 1999; revised June 22, 1999; accepted June 29, 1999.

This work was supported by Wellcome Trust. CGP55845 was kindly donated by Ciba Geigy.

Correspondence should be addressed to Prof. J.G.R. Jefferys, Department of Neurophysiology, Division of Neuroscience, The Medical School, The University of Birmingham, Birmingham B15 2TT, UK.

Copyright (C) 1999 Society for Neuroscience $0270-6474 / 99 / 198104-10 \$ 05.00 / 0$ caused by the population spike. (2) Pyramidal neurons located on the surface of the slice, where field effects are weak, fired repetitively but were not synchronized to the network activity. (3) A moderate decrease (50 mOsm) in artificial CSF (ACSF) osmolality did not affect the slow depolarization but increased oscillation amplitude and duration and recruited previously silent neurons into oscillations. (4) 50 mOsm increase in ACSF osmolality dramatically reduced, or abolished, post-tetanic oscillations. Phasic IPSPs, not detectable in proximal neurons, were present, late in the oscillation, in cells located 200-400 $\mu \mathrm{m}$ from the stimulation site and possibly contributed to slowing the rhythm during the $\gamma$ to $\beta$ transition.

Key words: $\gamma$ rhythms; neuronal networks; hippocampus; depolarizing GABA response; field effect (ephaptic) interactions; neuronal synchronization combining experiments and numerical simulations, post-tetanic $\gamma$ has been explained by incorporating pyramidal neurons into the interneuronal network used to describe glutamate-induced oscillations (Traub et al., 1996b, 1999; Whittington et al., 1997a,b). In this model, pyramidal neurons and interneurons are depolarized, primarily by mGluR activation. Mutual inhibition still plays an important role in synchronizing network firing but excitatory connections between pyramidal neurons and from pyramidal neurons to interneurons are also required and endow the network with important properties such as long-range synchrony and the ability to shift from $\gamma$ to $\beta$ frequency.

$\gamma$ rhythms induced by bath application of carbachol, kainic acid, and other agents have properties between those of glutamate and tetanically induced $\gamma$, in that pyramidal cells fire sparsely, typically on $\sim 5 \%$ of cycles (Fisahn et al., 1998). They differ in that they start in CA3 rather than CA1, although they can transmit to CA1 via the Shaffer collaterals. The principles developed in computer modeling of post-tetanic $\gamma$ apply to carbachol-induced $\gamma$.

Here we report evidence that sheds new light on the mechanisms of post-tetanic $\gamma$. We find that activation of $\mathrm{GABA}_{\mathrm{A}}$ receptors, rather than mGluRs, is mainly responsible for the slow depolarization that drives neurons to firing. The associated dramatic drop in input resistance shunts phasic postsynaptic potentials and limits their ability to synchronize network oscillations. Finally, we report evidence that nonsynaptic field effects (or "ephaptic interactions") play a major role in synchronizing the population spikes characteristic of post-tetanic $\gamma$ (Jefferys, 1995).

\section{MATERIALS AND METHODS}

Transverse hippocampal slices $(400 \mu \mathrm{m})$, were prepared from male Sprague Dawley rats (90-350 gm; anesthetized with ketamine and me- 
detomidine). Young rats (90-120 gm) were always used for experiments on submerged slices. Older rats $(180-350 \mathrm{gm})$ were normally used for experiments using the interface chamber, but key observations were repeated on young rats and revealed no differences between the age groups. Slices were maintained at $32-36^{\circ} \mathrm{C}$ in gassed $\left(5 \% \mathrm{CO}_{2}, 95 \% \mathrm{O}_{2}\right)$ ACSF containing (in mM): $\mathrm{NaCl}, 125 ; \mathrm{NaHCO}_{3}, 26 ; \mathrm{CaCl}_{2}, 2 ; \mathrm{KCl}, 3$; $\mathrm{NaH}_{2} \mathrm{PO}_{4}, 1.25 ; \mathrm{MgCl}_{2}, 1$; and glucose, 10. For intracellular recordings, slices were placed in an interface chamber. Sharp electrodes were filled with $2 \mathrm{M}$ potassium methylsulphate. For whole-cell recordings from visualized neurons, slices were placed on the glass base of a submersion chamber mounted on an Olympus upright microscope with a $40 \times \mathrm{im}-$ mersion objective and differential interface contrast optics. Patch pipettes contained (in $\mathrm{mM}$ ): potassium gluconate, 145; KCl, 10; HEPES, 10; $\mathrm{NaCl}, 2 ; \mathrm{Mg}$ ATP, 2; and EGTA, 0.1; $\mathrm{pH}=7.25$ (adjusted with $\mathrm{KOH})$. A bipolar Nichrome wire stimulating electrode was placed at the border between strata radiatum and pyramidale of the CA1 region (unless otherwise stated). The extracellular recording electrode (20-70 $\mu \mathrm{m}$ diameter, filled with ACSF) was placed on the surface of the stratum pyramidale $50-200 \mu \mathrm{m}$ from the stimulation site. The tetanus was 20 stimuli at $100 \mathrm{~Hz}$ (Whittington et al., 1997a). Stimulation intensity threshold $(\mathrm{T})$ was defined as the minimum intensity required for observing at least five rhythmic population spikes ( $\mathrm{T}$ range, 5-20 V, $0.1 \mathrm{msec}$ duration). Tetani were delivered at fixed intervals (3-5 min). Extracellular signals were bandpass-filtered $(1 \mathrm{~Hz}$ to $3 \mathrm{kHz})$. Sharp-electrode intracellular and whole-cell patch-clamp recordings were made using an Axoclamp 2B amplifier in bridge mode.

ACSF osmolality was measured by a freezing point depression osmometer (Advanced Instruments). Control ACSF osmolality was $295 \mathrm{mOsm}$. Hypotonic solution (245 mOsm) was obtained by addition of distilled water to control ACSF. Hypertonic solution $(345 \mathrm{mOsm})$ was obtained by addition of the appropriate amount of sucrose to the hypotonic or control ACSF. Data were stored and analyzed using Signal software (CED Ltd, Cambridge, UK). Statistical significance was assessed by oneway ANOVA (Sigmaplot, SPSS Inc). Data are expressed as mean \pm SD.

Instantaneous frequency was calculated from the interval between the negative peaks of two consecutive population spikes. Where the instantaneous frequency is plotted versus time, each value is temporally aligned with the second of the two consecutive population spikes used for that measurement. Local field potentials immediately adjacent to intracellularly recorded neurons were estimated from field potentials recorded at the surface of the slice in the following way. After loss of impalement, the intracellular electrode was left in place, and the stimulation protocol was repeated; this allowed simultaneous measurements of the field potentials just outside the previously recorded neuron and at the surface of the slice. Local fields recorded from the slice tissue were 3-8 times larger than those recorded superficially (the ratio between the two did not change during post-tetanic responses). A conversion factor accounting for this difference was calculated for each intracellular experiment, and the local field during previous intracellular recordings was estimated from simultaneous superficial recordings.

\section{RESULTS}

\section{General properties of post-tetanic oscillations}

Tetanic stimulation (20 pulses at $100 \mathrm{~Hz}$, delivered to strata pyramidale, radiatum, or oriens in the CA1 area) evoked rhythmic population spikes, recorded extracellularly from the stratum pyramidale, close to the stimulus site (Whittington et al., 1997a,b; Traub et al., 1999). Strong stimulation of two sites separated by $<2 \mathrm{~mm}$ (the maximum available in conventional transverse hippocampal slices) led to very fast $(<1 \mathrm{msec})$ synchronization of the $\gamma$ rhythms at the two sites (Traub et al., 1996b). Stimulation at twice threshold $(2 \times \mathrm{T}$; see Materials and Methods $)$, of either one or two sites, evoked oscillations initially in the $\gamma$ frequency band $(30-100 \mathrm{~Hz})$ and later slowing to the $\beta$ band $(10-30 \mathrm{~Hz})$, as in previous reports (Whittington et al., 1997b; Traub et al., 1999). The transition from $\gamma$ to $\beta$ activity typically was gradual (Fig. $1 A$ ). Similar gradual shifts have been reported previously (Traub et al., 1999), in addition to more abrupt cases (Whittington et al., 1997b). The plot of instantaneous frequency quantifies such a transition against time from the end of the tetanus (Fig. $1 B$, time-aligned with Fig. $1 A$; stimulus site here, and, unless other-

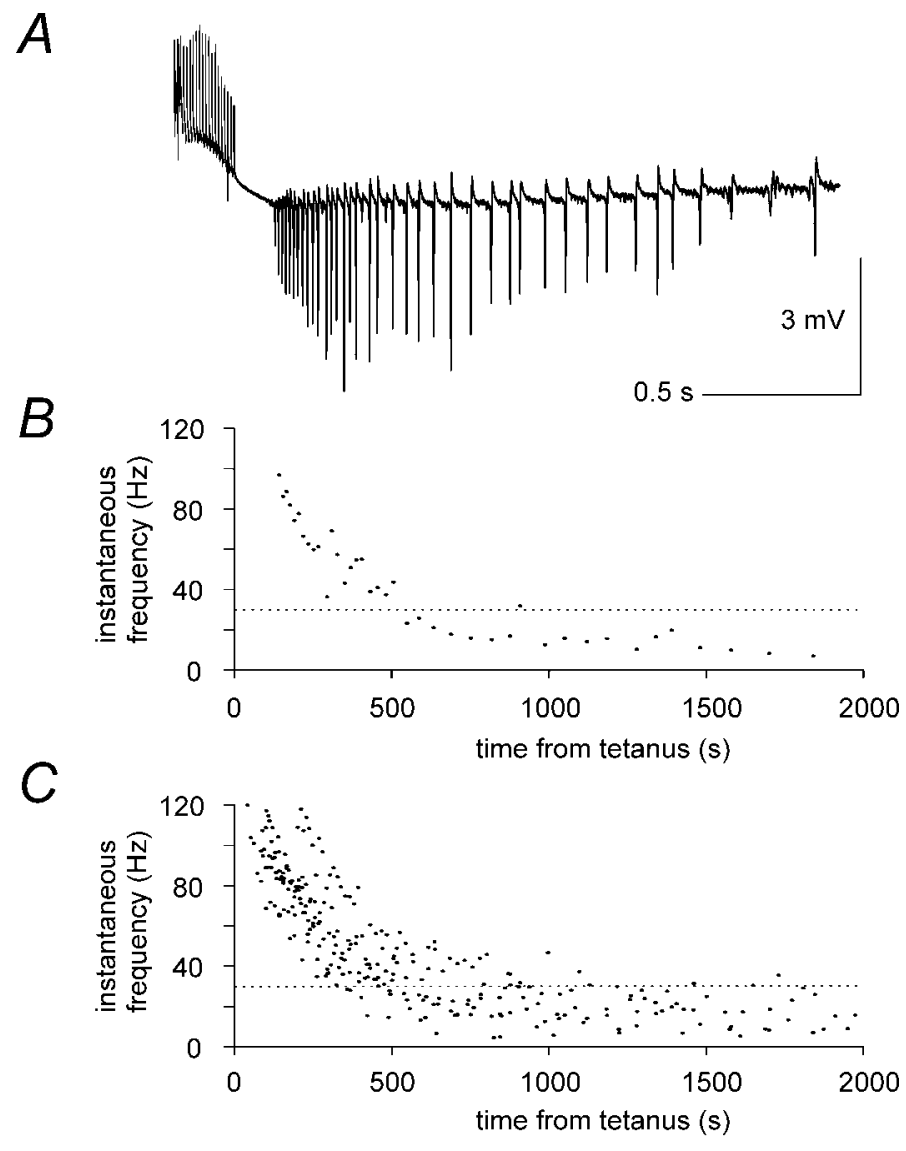

Figure 1. General features of tetanically induced oscillations. A, Typical tetanically induced oscillations (stimulation intensity, $2 \times \mathrm{T}$; artifacts are reduced here and in the next figures) recorded extracellularly from the CA1 pyramidal layer and displaying $\gamma$ to $\beta$ frequency transition. $B$, Plot of instantaneous frequency versus time from the end of the tetanus for the experiment in $A$. The time axes of $A$ and $B$ are aligned. The dotted line at $30 \mathrm{~Hz}$ in $B$ separates $\gamma$ and $\beta$ frequency ranges. $C$, Plot of instantaneous frequency obtained from eight slices stimulated at $2 \times \mathrm{T}$. Data from a single representative oscillation were included for each slice.

wise specified, throughout this paper, was at the border of strata pyramidale and radiatum). Values pooled from eight slices obtained from different animals $(2 \times \mathrm{T}$ stimulation intensity) are shown in Figure 1C. Stimulation intensities between 1 and $1.5 \times$ $\mathrm{T}$ gave rise to shorter oscillations that remained within the $\gamma$ frequency (Whittington et al., 1997b; Traub et al., 1999).

\section{Pharmacology of the slow depolarization}

Rhythmic population spikes result from synchronous action potentials of principal neurons. The neurons are brought to threshold by a slow depolarization that follows the tetanic stimulation (Whittington et al., 1997a). Such a slow depolarization had been previously attributed mainly to activation of mGluR (Whittington et al., 1997a). An increase in input resistance is expected for mGluR activation on CA1 principal neurons (Davies et al., 1995). However, we found that the slow depolarization (that was preceded by an early hyperpolarization; Fig. $2 A, E$ ) was accompanied by a dramatic reduction of input resistance (Fig. $2 A, C$; slow depolarization peak amplitude was $14.6 \pm 4.6 \mathrm{mV}$, peak time $584 \pm 257 \mathrm{msec}$ after the end of the tetanus; data obtained from 36 cells impaled within $200 \mu \mathrm{m}$ from the stimulation site, as in the rest of this section; the synchrony between principal neuron action potentials and population spikes during the slow depolar- 
A

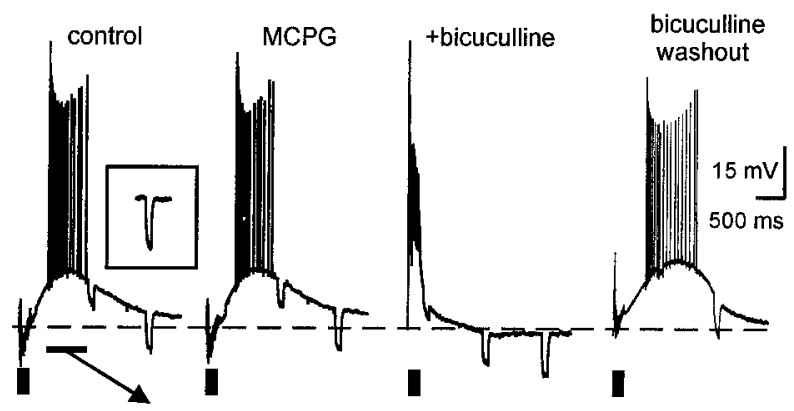

$B$

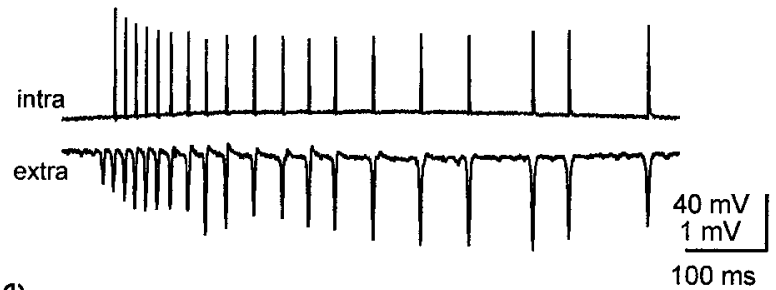

C

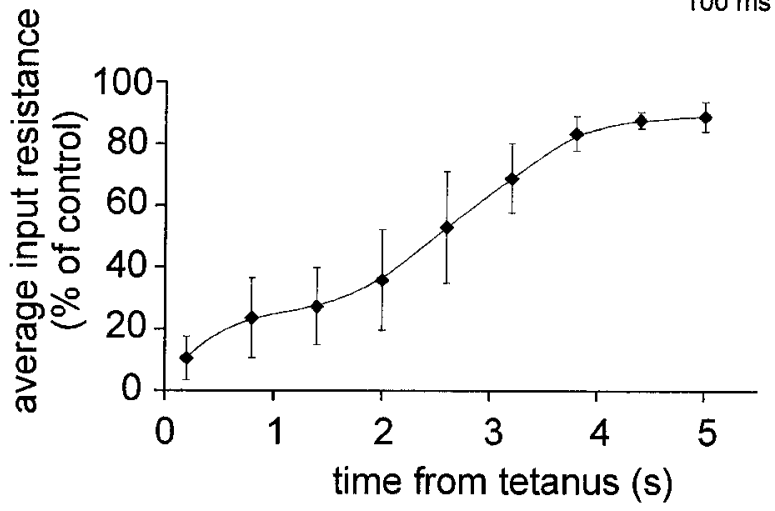

$D$

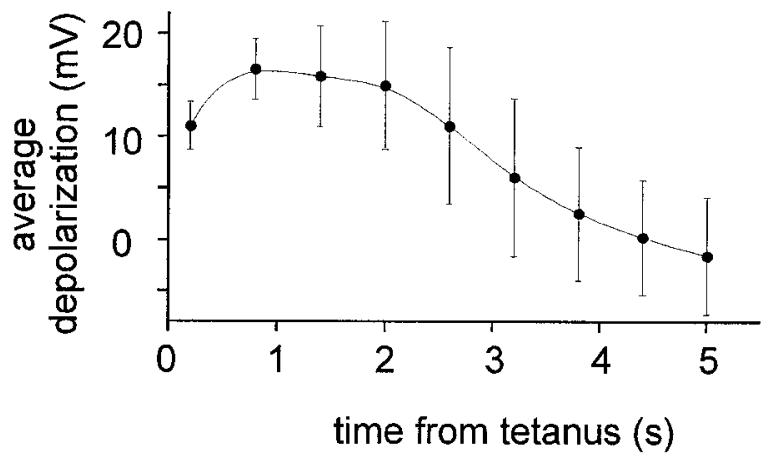

E

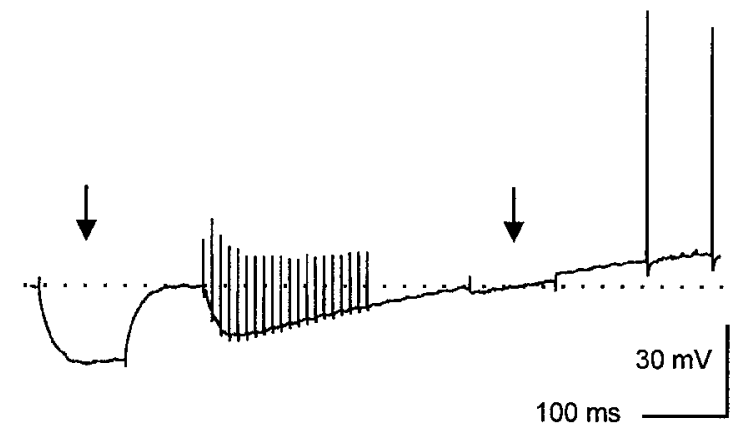

ization is illustrated in Fig. 2B). The average drop in input resistance and the average depolarization observed after tetanic stimulation are plotted versus time in Figure 2, $C$ and $D$, respectively (data pooled from eight neurons). The drop in input resistance was not caused by voltage-dependent properties of the membrane, because it was observed in cases when membrane potentials were close to the resting level at the end of the tetanic stimulation (Fig. 2E). The pooled data at 0.2 and $2.6 \mathrm{sec}$ in Figure 2, $C$ and $D$, confirm that changes in input resistance did not depend on changes in membrane potential.

In the period when rhythmic population spikes were observed (mainly during the first $2 \mathrm{sec}$ after the end of the tetanus), the input resistance of principal neurons was reduced to $5-40 \%$ of its pretetanic value. In contrast, bath application of the mGluR agonist ACPD $(50 \mu \mathrm{M})$ depolarized principal neurons by $11.2 \pm$ $3.2 \mathrm{mV}$ and caused a $25 \pm 9 \%$ increase in their input resistance ( $p<0.001 ; n=4$; data not shown). A drop in input resistance is expected for depolarizing GABA effects (Grover et al., 1993), that can be induced by similar stimulation protocols (40 stimuli at $100 \mathrm{~Hz}$ rather than 20 stimuli at $100 \mathrm{~Hz}$ used here; Kaila et al., 1997; Taira et al., 1997). As in these reports, the tetanically induced depolarization was preceded by an early hyperpolarization and was reversibly blocked (together with network oscillations) by the $\mathrm{GABA}_{\mathrm{A}}$ receptor antagonist bicuculline $(50 \mu \mathrm{M}$; Fig. $2 A ; n=11)$. In the presence of bicuculline the early hyperpolarization was replaced by a large amplitude, epileptiform depolarizing burst, that decayed rapidly after the tetanus and was also accompanied by a decrease in input resistance (Fig. $2 A$ ). When stimulation was delivered to the border of strata radiatum and pyramidale the slow depolarizations (and the network oscillations) were not affected by the broad spectrum mGluR antagonist MCPG ( $1 \mathrm{~mm} ; n=7)$, as shown in Figure $2 A$. Similar results were obtained when the ACSF was modified to contain $16 \mathrm{~mm}$ $\mathrm{NaHCO}_{3}$ and $135 \mathrm{~mm} \mathrm{NaCl}$, for better comparison with previous studies (Whittington et al., 1997a,b).

When the oscillations were evoked by tetanic stimulation of stratum oriens, the slow depolarizations were accompanied by a similar drop in input resistance and were abolished (together with the network oscillations) by bicuculline. However, in this case they

Figure 2. Depolarizing GABA effects are responsible for the slow depolarization. $A$, In control solution, tetanic stimulation (thick bar) elicited an early hyperpolarization (resulting from summed hyperpolarizing IPSPs) that was followed by a slow depolarization accompanied by repetitive firing (synchronized with the rhythmic population activity, see $B$ ) and by a dramatic drop in input resistance, which was monitored by -0.5 $\mathrm{nA}$ current pulses (not time locked to the stimulus, the inset shows the pretetanic response). Bath application of MCPG (1 mM) failed to affect the slow depolarization and the associated firing activity. Further application of bicuculline $(50 \mu \mathrm{M})$ converted the early hyperpolarization into a depolarizing burst and abolished the slow depolarization. This effect was reversed on washout (still in the presence of MCPG). $V_{\mathrm{m}}=-67 \mathrm{mV} . B$, A temporal expansion of the interval marked by the thin horizontal bar in $A$, showing that in control solution the firing activity associated with the depolarization was synchronized with the rhythmic population spikes (extra). A similar synchronization was observed in the presence of MCPG and during bicuculline washout (data not shown). $C$, Plot of average decrease in input resistance, estimated from $-0.5 \mathrm{nA}$ current pulses, during the period after the tetanus (data from 8 preparations, stimulation intensity $=2 \times \mathrm{T}$ ). $D$, Plot of average post-tetanic depolarization in the same set of cells used for $C$. $E$, Effects of two $-0.5 \mathrm{nA}$ current pulses (arrows) injected into a pyramidal neuron shortly before and after tetanic stimulation (vertical artifacts), at similar membrane potentials. Input resistance is dramatically reduced after the tetanus, at the onset of the slow depolarization. 
also were reduced by $1 \mathrm{~mm}(s)$ - $\alpha$-methyl-4-carboxyphenylglycine (MCPG) (depolarization peak amplitude was reduced by $14 \pm$ $9 \% ; n=4 ; p<0.05$; data not shown), presumably because of reduced excitability of local GABAergic interneurons. These data show that the slow depolarization of principal neurons is mainly mediated by $\mathrm{GABA}_{\mathrm{A}}$ receptors.

Prolonged application of the carbonic anhydrase inhibitor ethoxyzolamide (EZA) is known to depress GABA-induced depolarization (Kaila et al., 1997). Consistent with this observation, we found that EZA completely abolished $\gamma$ oscillations $(100 \mu \mathrm{M}$ for $>30 \mathrm{~min} ; n=3$ ).

\section{Effects of ionotropic glutamate receptor antagonists}

Previous studies have focused on the role of rhythmic, phasic EPSPs and IPSPs in synchronizing tetanically evoked $\gamma$ and $\beta$ oscillations (Whittington et al., 1997a,b). However, the present observations on the GABAergic nature of the tonic depolarizing drive and the associated drop in input resistance suggest that, during $\gamma$ activity, the influence of phasic synaptic potentials on cell excitability should be more limited than previously thought. This observation prompted investigation on the role of fast synaptic potentials in post-tetanic oscillations.

The role of fast inhibitory potentials could not be assessed directly by means of $\mathrm{GABA}_{\mathrm{A}}$ antagonists, because these agents also abolished the tonic GABAergic depolarizing drive preventing post-tetanic oscillations. To test the role of fast synaptic excitation, NMDA and non-NMDA ionotropic glutamate receptors (iGluRs) were blocked by bath application of $50 \mu \mathrm{M}$ D-AP-5 and $50 \mu \mathrm{M}$ NBQX, respectively. These antagonists blocked posttetanic oscillations elicited by $1.5-2 \times \mathrm{T}$ stimulation $(n=8)$, as previously described (Whittington et al., 1997a). The addition of iGluR antagonists is known to block polysynaptic IPSPs, leaving monosynaptic IPSPs caused by the direct stimulation of interneurons (Davies et al., 1990). The resultant decrease in GABA release onto principal neurons will reduce the tonic post-tetanic depolarization, thus possibly explaining the suppression of oscillations by NBQX and D-AP-5. We, therefore, increased stimulusevoked GABA release by two different procedures: addition of the $\mathrm{GABA}_{\mathrm{B}}$ antagonist CGP55845 $(1 \mu \mathrm{M})$ to decrease presynaptic inhibition of GABAergic terminals (Davies and Collingridge, 1993; Lambert and Wilson, 1994) and doubling the stimulus intensity, to activate more interneuronal terminals and thus increase GABA release onto pyramidal cells. Both treatments restored post-tetanic oscillations, in the presence of iGluR antagonists, in all slices tested (Fig. $3 A, B$, respectively). Intracellular recordings from neurons located within $200 \mu \mathrm{m}$ from the stimulation site $(n=4)$ revealed that application of NBQX and D-APV reduced the amplitude of the slow depolarization by $61 \pm 19 \%$. The depolarization could be restored to control levels by application of CGP55845 with slight adjustments of stimulation intensity. When the amplitude of the slow depolarization was restored by such a procedure in the presence of iGluR antagonists, the drop in input resistance was not significantly different from control during the first $800 \mathrm{msec}$ after the end of the tetanus. However, the recoveries from the drop in resistance and the depolarization were more rapid in the presence of iGluR antagonists than in control ACSF. iGluR antagonists decreased the time for $50 \%$ recovery from $2.3 \pm 0.6 \mathrm{sec}$ to $1.1 \pm 0.2 \mathrm{sec}$ for input resistance $(p<0.05)$, and from $2.7 \pm 0.9 \mathrm{sec}$ to $1.9 \pm 0.9 \mathrm{sec}$ (not significantly different) for the slow depolarization. Presumably these effects of iGluR antagonists were related to disruption of prolonged GABA release from polysynaptic pathways, with late

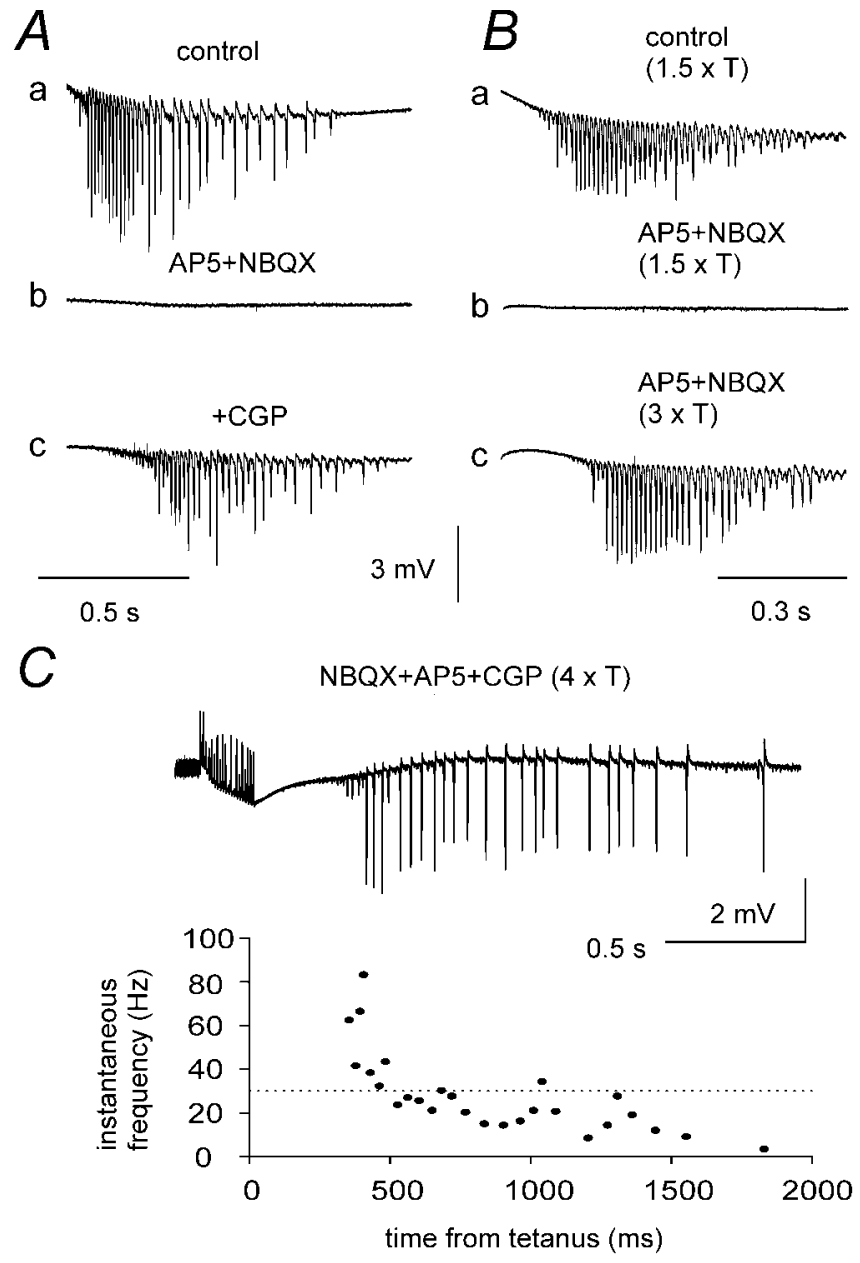

Figure 3. Effects of iGluR antagonists on post-tetanic oscillations. $A$, Post-tetanic oscillations $(a$; stimulation intensity $=2 \times \mathrm{T})$ were blocked by coapplication of $50 \mu \mathrm{M}$ D-AP-5 and $50 \mu \mathrm{M}$ NBQX $(b)$. Further addition of $1 \mu \mathrm{M}$ CGP55845 restored rhythmic activity $(c)$. $B$, oscillations induced by $1.5 \times \mathrm{T}$ stimulation $(a)$ were blocked in another slice by the same doses of D-AP-5 and NBQX $(b)$, but resumed when the stimulation intensity was doubled (c). $C$, A prominent $\beta$ shift recovered when both CGP55845 and increased stimulation were applied in a different slice exposed to D-AP-5 and NBQX.

accumulation of extracellular potassium playing a more prominent role in the presence of these agents (Kaila et al., 1997).

These results show that iGluR antagonists blocked post-tetanic oscillations by affecting the slow GABAergic depolarization, and that phasic excitatory synaptic potentials were not required for this rhythmic activity. Previous studies have suggested that fast excitatory synaptic potentials between pyramidal neurons play an essential role in the generation of $\beta$ oscillations (Whittington et al., 1997a,b). However, application of CGP55845 in the presence of NBQX and D-AP-5 restored $\gamma$ to $\beta$ frequency transitions in five of six cases (two of the five required an increase in stimulus strength to 3-4 $\times$ T; Fig. $3 C$ ). These data show that the CA1 neuronal network can produce oscillations at both $\gamma$ and $\beta$ frequency even when fast glutamatergic transmission is blocked.

To cast light on the role of phasic IPSPs, electrical stimuli were applied to stratum pyramidale every $500 \mathrm{msec}$ before and after tetanic stimulation in the presence of NBQX, D-AP-5 and CGP55845. Intracellular recordings from pyramidal cells impaled within a distance of $200 \mu \mathrm{m}$ from the stimulus site revealed a 


\section{monosynaptic IPSPS}

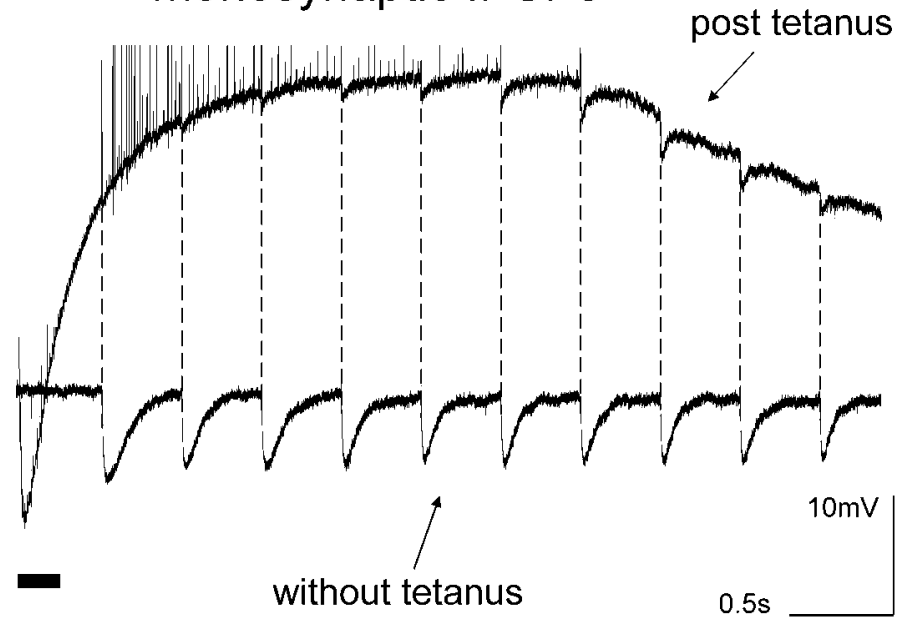

Figure 4. Suppression of IPSPs after tetanic stimulation. Stimulation at $0.5 \mathrm{~Hz}$ delivered to pyramidal layer in the presence of NBQX, D-AP-5, and CGP55845 before tetanic stimulation (bottom trace) elicited IPSPs characterized by a mild use-dependent depression in a pyramidal neuron $\left(V_{\mathrm{m}}=-65 \mathrm{mV}\right)$. When the same protocol was applied during the slow depolarization induced by tetanic stimulation, evoked IPSPs were initially suppressed and remained extremely small during the first $2 \mathrm{sec}$ after the end of the tetanus.

dramatic reduction in the amplitude of evoked monosynaptic IPSPs during the post-tetanic oscillations and the associated slow depolarization (Fig. 4). In the absence of tetanic stimulation, monosynaptic IPSPs evoked at $0.5 \mathrm{~Hz}$ displayed a moderate use-dependent depression and quickly settled at an amplitude $60-80 \%$ of the first IPSP (Davies and Collingridge, 1993). During the first $1000 \mathrm{msec}$ after the tetanus, however, IPSPs were reduced to $<10 \%$ of the control value, and often were suppressed entirely. Evoked IPSPs remained much smaller than those recorded in the absence of tetanic stimulation for $>5 \mathrm{sec}$. On average, evoked IPSPs amplitude $300 \mathrm{msec}$ after the end of the tetanus was reduced to $4.9 \pm 4.2 \%$ of its control value $(n=8 ; p<$ 0.001).

Several factors could have contributed to such post-tetanic IPSPs suppression including decreased input resistance of the postsynaptic cells, a positive shift of its $\mathrm{GABA}_{\mathrm{A}}$ receptor reversal potential (Staley et al., 1995; Kaila et al., 1997), and tetanusinduced, use-dependent presynaptic depression (Davies and Collingridge, 1993). This observation, together with persistence of $\gamma$ and $\beta$ oscillations in the presence of iGluR antagonists, suggested that network mechanisms different from chemical synapses could be involved in the synchronization of this rhythmic activity.

\section{Role of field effect (ephaptic) interactions}

During post-tetanic oscillations (evoked by $2 \times \mathrm{T}$ stimulation), action potentials synchronized with population spikes were recorded with sharp microelectrodes from 23 of 36 pyramidal neurons impaled within $200 \mu \mathrm{m}$ from the stimulating electrode and deeply embedded in the slice tissue $(>50 \mu \mathrm{m}$ from the slice surface). In some cells partial spikes (also synchronized with population spikes) coexisted with full blown spikes (some partial spikes are apparent in Fig. 4). The remaining cells did not fire during the slow depolarization. Action potentials arose either abruptly from the baseline or from brief negative deflections; in these neurons phasic synaptic potentials were not detectable during post-tetanic oscillations. Figure $5 A$ shows simultaneous
$A$
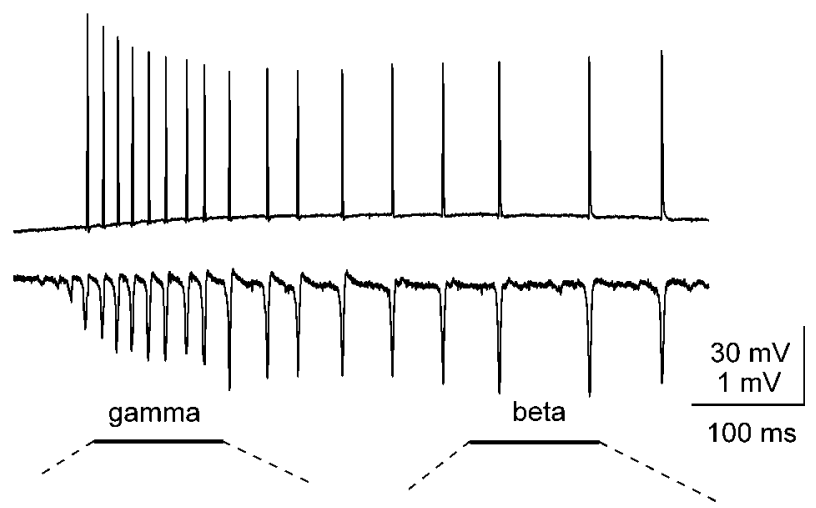

$B$

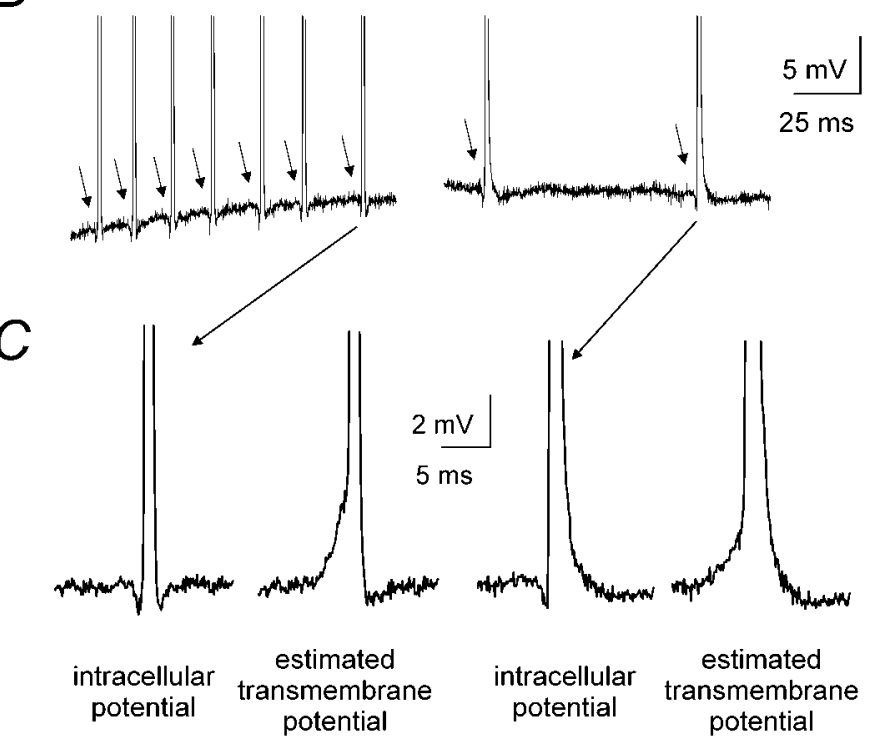

Figure 5. Negative deflections precede action potentials in pyramidal neurons participating to the oscillation. $A$, Simultaneous intracellular and extracellular recordings showing an oscillation evoked by $2 \times \mathrm{T}$ stimulation intensity and undergoing a $\gamma$ to $\beta$ transition. The principal cell $\left(V_{\mathrm{m}}=\right.$ $-65 \mathrm{mV}$ ) generated action potentials synchronized with rhythmic population spikes. $B$, Expansions of intracellular recording from $A$ show apparent hyperpolarizations (arrows) preceding each action potential during both the $\gamma($ left $)$ and $\beta$ (right) phases. $C$, One action potential is expanded from the $\gamma$ phase and one from the $\beta$ phase. To the right of each is the transmembrane potential, estimated by subtracting the simultaneous local field potential (see Materials and Methods). Note that the initial apparent hyperpolarization corresponds to a net transmembrane depolarization.

intracellular and extracellular recordings during a typical oscillation comprising population spikes at $\gamma$ and $\beta$ frequencies. Irrespective of their frequency, the action potentials were preceded by negative deflections (Fig. $5 B$ ), which coincided exactly with the population spikes. Such deflections, typical of ephaptic interactions, are recorded with respect to a distal ground electrode and mask a net transmembrane depolarization that can bring the neuron above firing threshold if a larger negative potential exists just outside the neuron (Taylor and Dudek, 1984a; Faber and Korn, 1989; Jefferys, 1995). The transmembrane potential is estimated by subtracting the field potential just outside the neuron (see Materials and Methods) and reveals that the negativity just before action potentials corresponds to a net depolarization, during both $\gamma$ and $\beta$ activity (Fig. $5 C$ ). The densely packed, geometrically layered arrangement of CA1 neurons endows them 
with the ability to excite each other strongly during firing activity, because of the summation of extracellular currents flowing perpendicular to the cell layers (Traub et al., 1985; Faber and Korn, 1989; Jefferys, 1995). These field effects are predicted to be stronger when the extracellular resistance is larger. To evaluate the role of field effects in the synchronization of tetanically induced oscillations, we tested experimental conditions in which the extracellular resistance was predictably raised or lowered from control.

Fields near the surface of the submerged hippocampal slice are shunted by a large volume of ACSF, which provides a lowresistance extracellular pathway. In submerged slices, tetanically evoked oscillations had consistently lower population spike amplitudes than those in the interface chamber. Neurons located at the surface of the submerged slice should, therefore, be relatively weakly affected by field effects during population spikes. Wholecell recordings were obtained from superficial pyramidal neurons during tetanically induced oscillations $(2 \times \mathrm{T}$ stimulation intensity) within $200 \mu \mathrm{m}$ from the stimulation site. These cells displayed post-tetanic depolarizations that were similar in amplitude and time course to those recorded from deep pyramidal neurons. These depolarizations were blocked by bicuculline $(50 \mu \mathrm{M})$, insensitive to the mGluR antagonist MCPG (1 mM), and accompanied by a dramatic drop in input resistance with a time course similar to the one described in Figure $1 C$. Superficial pyramidal neurons fired action potentials during the slow depolarization in 10 of 14 cases. In 6 of 14 cases, firing activity reached frequencies between 40 and $105 \mathrm{~Hz}$. However, their action potentials were not phase-locked with the rhythmic population spikes. Despite lack of synchronization, superficial neurons fired at frequencies similar to those of the underlying population spikes (as shown in the example of Fig. $6 A, B)$. The action potential instantaneous frequency plot of Figure $6 C$ was obtained by pooling data from the six neurons that fired at $\gamma$ frequencies during post-tetanic depolarization. It shows that nonsynchronized neurons fired with frequencies successively covering both $\gamma$ and $\beta$ bands.

Extracellular resistance (and therefore field effects) can be manipulated by changing extracellular osmolality. Cellular swelling, caused by hypotonic solutions, increases extracellular resistance and enhances electrical interactions, whereas opposite effects result from cellular shrinking caused by hypertonic solution (Traynelis and Dingledine, 1989; Ballyk et al., 1991; Jefferys, 1995). To test the role of field effects in generating $\gamma$ oscillations, we modified the osmolality of the extracellular solution by \pm 50 mOsm by adding distilled water and/or sucrose to the ACSF. Such modifications do not introduce major changes in the intrinsic and synaptic properties of CA1 pyramidal neurons, but do significantly affect field effects (Ballyk et al., 1991).

Hypotonic ACSF significantly $(p<0.001)$ prolonged $\gamma$ oscillations and increased population spike amplitudes within them (Fig. 7A). Despite the increased amplitude and area, population spike width at half amplitude decreased significantly $(p<0.001)$ in hypotonic solution, confirming an increase in spike synchrony (Fig. 7B; measurements from seven slices, from seven different rats are pooled in Fig. $7 C$ ). Hypotonic ACSF also reduced the threshold stimulation intensity for rhythmic oscillations significantly (by $34 \pm 9 \% ; p<0.001$ ) and reduced the oscillation frequency (by $26 \pm 15 \%$; $p<0.05$ in each slice). Subsequently increasing extracellular osmolality with sucrose invariably caused a dramatic decrease in population spike amplitude and in the duration of rhythmic activity (Fig. $7 A$ ). Hypotonic and hypertonic

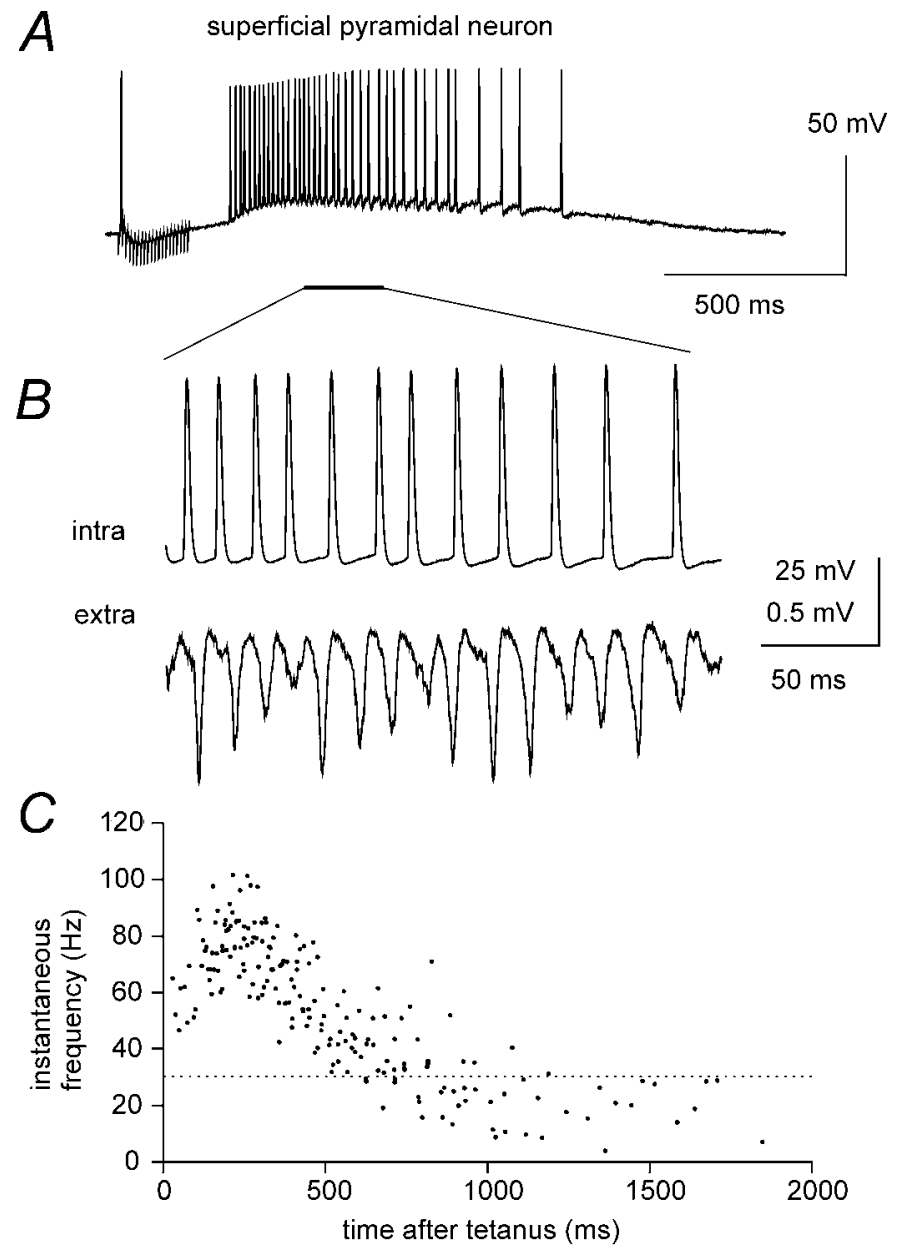

Figure 6. Action potentials in superficial neurons are not synchronized with population activity. $A$, Whole-cell recordings from a superficial pyramidal neuron $\left(V_{\mathrm{m}}=-62 \mathrm{mV}\right)$ in a submerged slice show a slow depolarization after tetanic stimulation $(2 \times \mathrm{T})$, accompanied by repetitive firing. $B$, A temporal expansion shows that the action potentials took place with a frequency similar to that of extracellularly recorded population spikes, but were not time-locked to these events. $C$, Action potential instantaneous frequency plot containing data from single post-tetanic responses for each of six superficial pyramidal neurons from different slices.

ACSF exerted similar effects on the oscillations in the presence of NBQX, D-AP-5 and CGP55845 (data not shown).

Intracellular recordings from pyramidal neurons showed that the tetanically evoked, slow depolarizations were not significantly affected by changes in extracellular osmolality (depolarization peak amplitude was $17 \pm 7 \mathrm{mV}$ in control ACSF and $16 \pm 6 \mathrm{mV}$ in hypotonic ACSF, $n=5$; see also the example of Fig. $8 A$ ). Nonetheless, application of hypotonic solution was able to recruit previously silent neurons into the rhythmic population firing, both in the $\gamma$ band (Fig. $8 A$ ) and the $\beta$ band (Fig. $8 B$ ). In the presence of hypotonic ACSF, pyramidal cell action potentials (absent in control) were synchronized with the larger amplitude population spikes (see expansion of Fig. $8 A$ ). These observations demonstrate that field effects can effectively synchronize neurons during both $\gamma$ and $\beta$ activity.

\section{Synaptic potentials in distant neurons}

As previously mentioned, phasic IPSPs were not detectable during post-tetanic oscillations in neurons located close to the stim- 

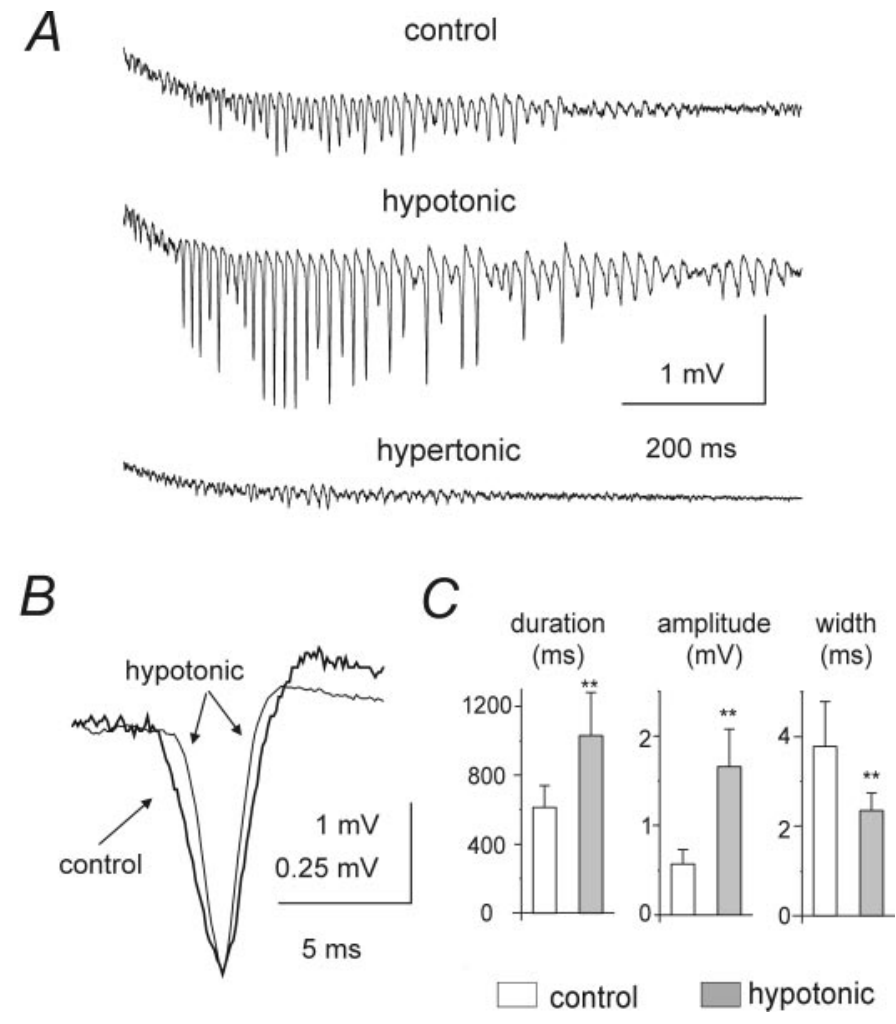

Figure 7. Effects of changes in osmolality on post-tetanic oscillations. A, Hypotonic ACSF application greatly increased population spike amplitude and oscillation duration (stimulation intensity $=2 \times \mathrm{T}$ ). Subsequent superfusion with hypertonic ACSF almost abolished the oscillation. $B$, When normalized to the same amplitude, population spikes recorded in hypotonic solution (thin line) revealed faster kinetics than in control ACSF, indicating greater synchronization. $C$, Average effects of hypotonic ACSF on oscillation duration, population spike amplitude, and population spike half width. Data were pooled from seven preparations.

ulation site $(<200 \mu \mathrm{m} ; n=36$; with $2 \times$ T stimulation). Pyramidal neurons $(n=12)$ located $200-400 \mu \mathrm{m}$ from the stimulus site (at depths $>50 \mu \mathrm{m})$ underwent a slow post-tetanic depolarization with similar pharmacological properties (i.e., depolarizing GABA) as described for more proximal neurons. However, these more distal pyramidal cells recovered more rapidly from the associated drop in input resistance. Input resistance measured $200 \mathrm{msec}$ after the end of the tetanus did not differ significantly between 10 proximal and 9 distal neurons $(8 \pm 3 \%$ and $15 \pm 3 \%$ of control value, respectively). However, after $1200 \mathrm{msec}$, input resistance was much lower in proximal neurons $(21 \pm 4 \%$ of control value) than in distant neurons $(56 \pm 4 \% ; p<0.001)$.

In 7 of 12 cases, pyramidal cells located $200-400 \mu \mathrm{m}$ from the stimulation site displayed discernible, rhythmic IPSPs phaselocked to the population spikes during the oscillations evoked by tetanic stimulation $(2 \times \mathrm{T})$. Such IPSPs were not detectable during the first, fast phase of the oscillation, but appeared when the frequency of the oscillation had slowed down to $<40 \mathrm{~Hz}$, concomitant with the gradual recovery of input resistance. This behavior is illustrated in Figure 9, where a cell located $\sim 300 \mu \mathrm{m}$ from the stimulation site started to display rhythmic IPSPs (indicated by arrows) when the frequency of the oscillation had slowed down to $\sim 20 \mathrm{~Hz}$. In 6 of 12 neurons located $>200 \mu \mathrm{m}$ from the stimulation site, rhythmic EPSPs time-locked to population spikes were also observed late in the post-tetanic oscillation (data not shown). It appears likely that these phasic post synaptic

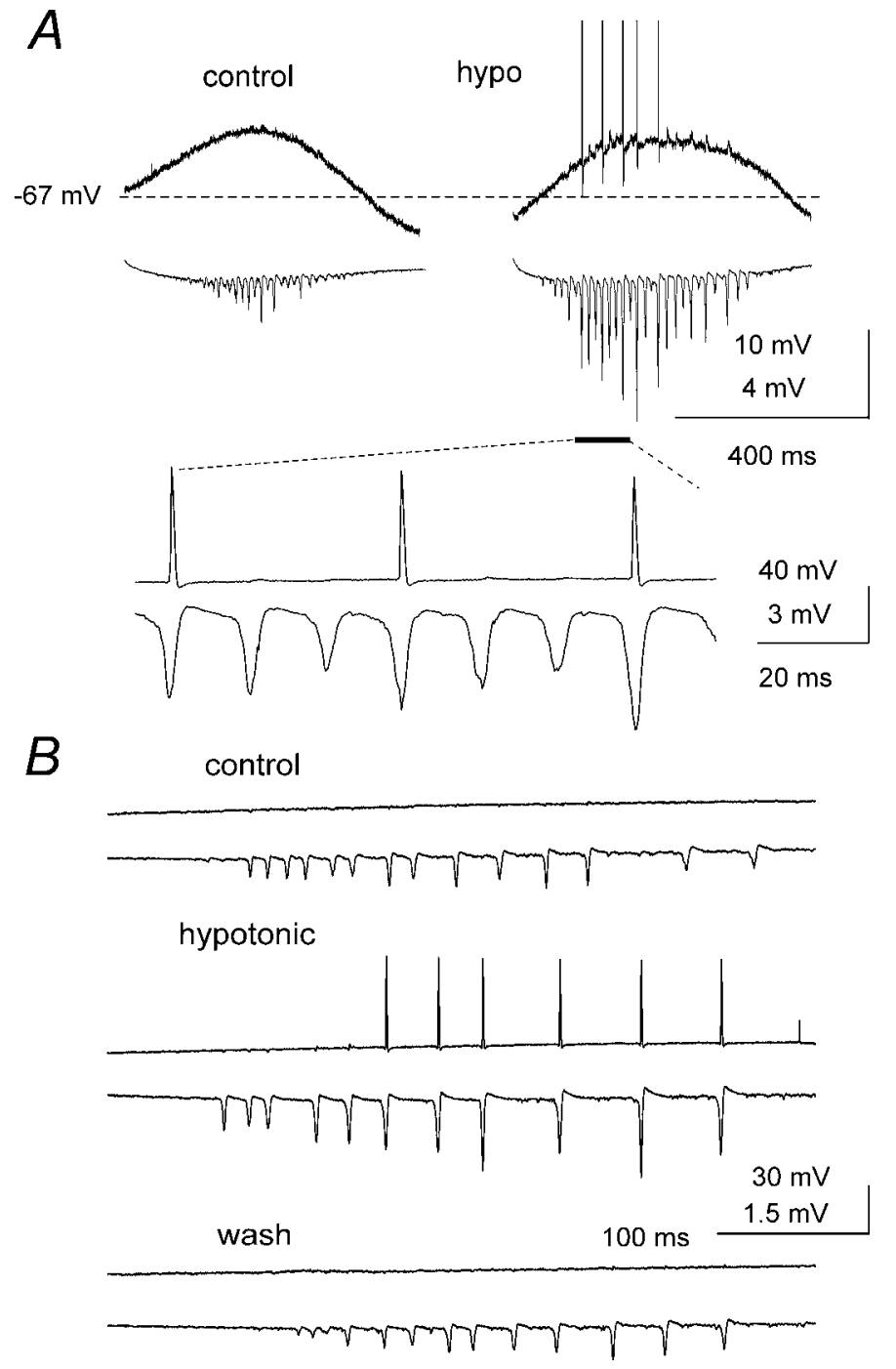

Figure 8. Recruitment of pyramidal neurons into population activity by hypotonic ACSF. A, Simultaneous intracellular (top traces) and extracellular recordings illustrating the effects of hypotonic ACSF on post-tetanic $\gamma$ oscillations elicited by $1.5 \times \mathrm{T}$ stimulation. Although the slow depolarization was not affected by decreased osmolality, the neuron, which was silent in control ACSF, generated several action potentials synchronized with the largest of the enhanced population spikes, as shown in the expansion. $V_{\mathrm{m}}=-67 \mathrm{mV} . B$, In this example $2 \times \mathrm{T}$ tetanic stimulation produced $\gamma$ and $\beta$ oscillations in control ACSF, but the slow intracellular depolarization failed to discharge the impaled neuron. In the presence of hypotonic ACSF, population spike amplitude increased and the neuron was recruited into collective activity during the $\beta$ phase, an effect that was reversible on washout. $V_{\mathrm{m}}=-64 \mathrm{mV}$.

potentials (PSPs) resulted from the massive, rhythmic activation of principal neurons and interneurons synchronized by field effects in the region closer to the stimulation site.

\section{DISCUSSION}

The present study demonstrates that oscillations evoked in the CA1 region by tetanic stimulation depend on (1) tonic depolarization mediated by $\mathrm{GABA}_{\mathrm{A}}$ receptors to make pyramidal neurons fire repetitively and (2) electric field effects to synchronize the large, rhythmic population spikes characteristic of posttetanic oscillations at $\gamma$ and $\beta$ frequencies. IPSPs recover late in the response, in cells $>0.2 \mathrm{~mm}$ from the stimulation site, and may contribute to the slowing from $\gamma$ to $\beta$ frequencies. 


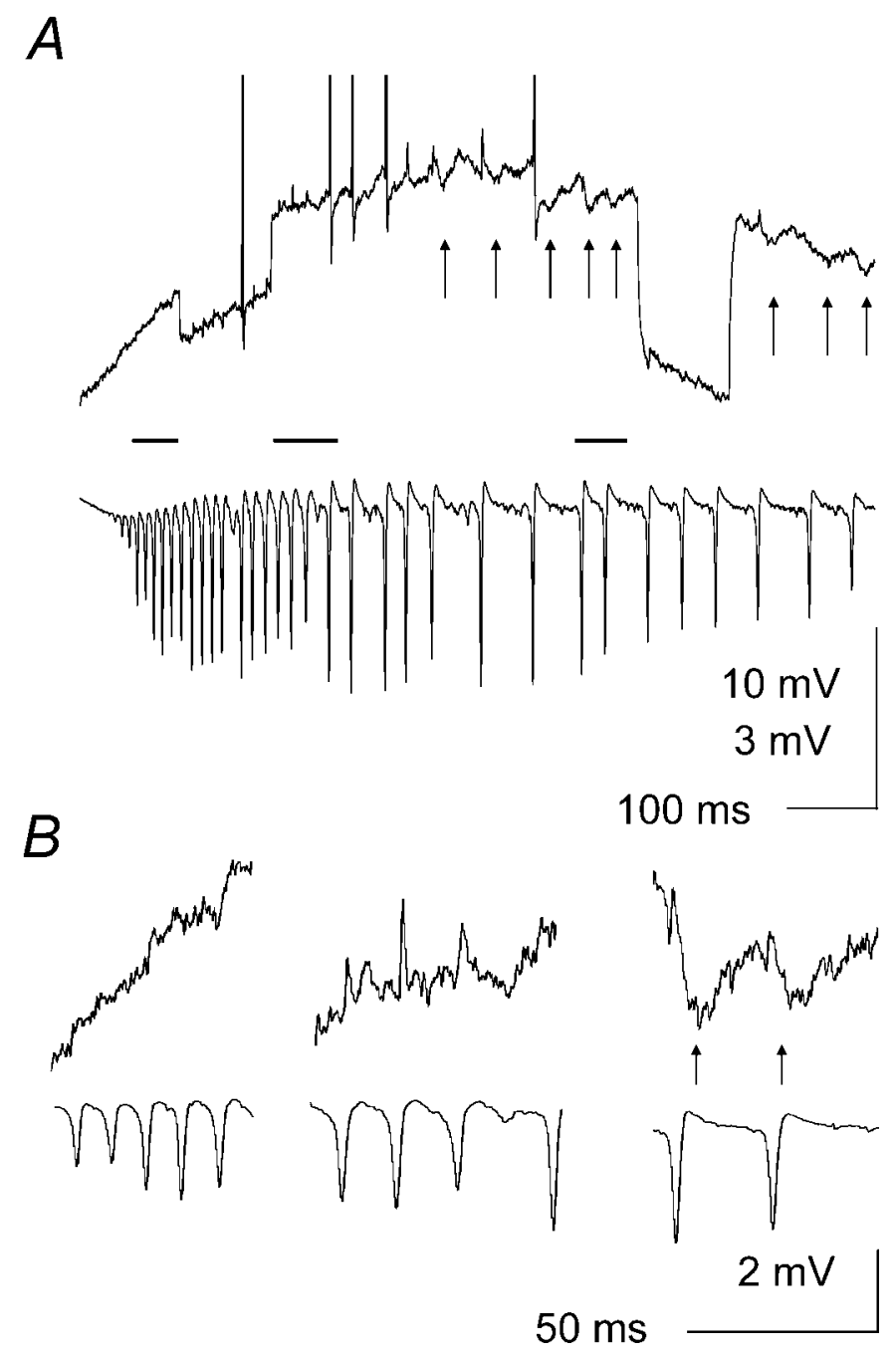

Figure 9. Rhythmic IPSPs in distant pyramidal neurons. A, Simultaneous intracellular (top traces) and extracellular recordings obtained $\sim 300 \mu \mathrm{m}$ from the stimulation site. Rhythmic population spikes and a slow depolarization were evoked by $2 \times \mathrm{T}$ tetanic stimulation (with some action potentials synchronized with population spikes) in the recorded pyramidal neuron. After the first $\sim 300 \mathrm{msec}$ of the slow depolarization, rhythmic IPSPs (arrows) started to appear, time-locked to population spikes, and continued for the duration of the $\beta$ phase of the oscillation $\left(V_{\mathrm{m}}=-66 \mathrm{mV}\right.$; input resistance monitored by $-0.5 \mathrm{nA}$ current pulses). $B$, Expansions of the periods marked by horizontal bars in $A$ (in order from left to right) reveal that although IPSPs were not detectable during the early, fast phases of the oscillation, they became clearly recognizable later on, when input resistance was partially recovered. Vertical calibration in $B$ applies to both intracellular and extracellular traces.

\section{Slow depolarization}

The slow depolarization and the rhythmic population spikes evoked by tetanic stimulation both were blocked completely by the $\mathrm{GABA}_{\mathrm{A}}$ receptor antagonist bicuculline. They were not blocked by mGluR antagonists at any site, and were only attenuated when the stimulus site was in stratum oriens, perhaps related to the high sensitivity to mGluR agonists of inhibitory neurons in that layer (McBain et al., 1994; Blasco-Ibanez and Freund, 1995). Previous reports identified mGluR as the main source of depolarization in both pyramidal and inhibitory neurons (Whittington et al., 1997a). This discrepancy likely arises because the previous work used oriens stimulation where interneurons rich in mGluRs will provide a large component of the
GABAergic depolarization of pyramidal cells. Similar considerations apply to iGluR antagonists, which also attenuated, but did not prevent, post-tetanic $\gamma$ and $\beta$ oscillations. The marked decrease in input resistance is consistent with depolarization mediated by $\mathrm{GABA}_{\mathrm{A}}$ receptors. Depolarizing actions of GABA (Alger and Nicoll, 1979; Cherubini et al., 1991) are well documented, and are attributed to accumulation of intracellular chloride (Staley et al., 1995) and extracellular potassium (Kaila et al., 1997) after prolonged activation of $\mathrm{GABA}_{\mathrm{A}}$ receptors.

\section{Field effects}

A crucial role for field effects (Faber and Korn, 1989; Jefferys, 1995) in post-tetanic $\gamma$ is demonstrated by population spikedriven transmembrane depolarizations preceding the majority of action potentials, failure of superficial neurons in submerged slices to synchronize, and the selective effects of modest changes in osmolality. Synchronization by field effects occurred during both $\gamma$ and $\beta$ post-tetanic oscillations, resulting in the characteristic large, fast, rhythmic population spikes (Traub et al., 1996b; Whittington et al., 1997a).

Field effects were first revealed in slices bathed in low calcium, to block chemical synapses and to raise excitability. The resultant "field bursts" generated large, rhythmic population spikes similar to those in post-tetanic $\gamma$ (Haas and Jefferys, 1984; Taylor and Dudek, 1984b). Realistic numerical simulations of CA1 field bursts have shown that endogenous electric fields can synchronize neuronal firing, within a millisecond time scale, in the absence of synaptic transmission (Traub et al., 1985). Since the efficacy of ephaptic coupling depends on the ratio between the resistances of the extracellular and intracellular current paths (Traub et al., 1985; Faber and Korn, 1989), it may be enhanced by the drop in input resistance observed during post-tetanic oscillations in the present study. Field effects are expected to be more pronounced in vivo, where shunting is less, and fields can get much larger (Jefferys, 1995).

\section{Role of phasic synaptic potentials}

The drop in input resistance during the tonic GABAergic depolarization will reduce the influence of phasic synaptic potentials. This is important because phasic synaptic potentials play a crucial role in a well-established model of $\gamma$ oscillations, in which the slow depolarization was attributed primarily to mGluR activation (Traub et al., 1996a,b; Whittington et al., 1997a).

iGluR antagonists can block post-tetanic oscillations (Traub et al., 1996a; Whittington et al., 1997a), but rhythmic activity was re-established here by application of a $\mathrm{GABA}_{\mathrm{B}}$ antagonist or by increasing stimulation intensity, restoring the amount of GABA released (Davies et al., 1990; Davies and Collingridge, 1993; Lambert and Wilson, 1994). We conclude that the reversible block of oscillations by iGluR antagonists was caused by suppression of polysynaptic IPSPs (Davies et al., 1990), decreased GABA release and, therefore, depolarizing GABAergic potentials (Kaila et al., 1997). Strong tetanic stimulation resulted in a gradual $\gamma$ to $\beta$ transition (see also Whittington et al., 1997b). This has been previously attributed to long-term potentiation of mutual excitatory connections between pyramidal neurons (Whittington et al., 1997b; Traub et al., 1999). In the present study, however, $\gamma$ to $\beta$ transitions survived iGluR antagonists in the presence of CGP55845 and adequately increased stimulation. We conclude that the network does not require fast excitatory connections to oscillate at $\gamma$ and $\beta$ frequency.

Evoked monosynaptic IPSPs were dramatically reduced during 
post-tetanic oscillations. The drop in input resistance plays a major role. Contributions also could come from positive shifts of the $\mathrm{GABA}_{\mathrm{A}}$ receptor reversal potential after tetanic stimulation (Staley et al., 1995; Kaila et al., 1997), and presynaptic depression of inhibitory terminals because of their high frequency activation during the tetanus (Davies et al., 1990; Davies and Collingridge, 1993). The dramatic reduction of phasic IPSPs makes their involvement in controlling network rhythmicity unlikely, especially early in the oscillation and close to the stimulation site, when their suppression is virtually complete.

Although phasic IPSPs were absent in the neurons impaled $\leq 200 \mu \mathrm{m}$ from the stimulation site, they were observed in more distant principal cells during the late, slower phase of the oscillation, when the membrane input resistance had partially recovered. Hyperpolarizing IPSPs have been reported during slow GABA-mediated depolarizations. Accumulation of extracellular potassium prolongs the slow depolarization, whereas $\mathrm{GABA}_{\mathrm{A}}$ conductances decrease with GABA removal. This results in the $\mathrm{GABA}_{\mathrm{A}}$ receptor reversal potential becoming more negative than membrane potential (Kaila et al., 1997). These phasic IPSPs most likely are caused by ephaptic activation of interneurons. They coincide with the slowing of the rhythm to below $40 \mathrm{~Hz}$ and may contribute to prolonging the cycle period during this process. Addressing this issue will require a detailed investigation of the way in which the local networks located at different distances from the stimulation site interact together. The interpretation of the experiments involving $\mathrm{GABA}_{\mathrm{A}}$ receptor modulators, such as barbiturates and benzodiazepines (Whittington et al., 1996; Faulkner et al., 1998), is greatly complicated by the fact that these agents will affect not only phasic IPSPs but also the slow depolarization.

These results show that field effects play an essential role in the synchronization of pyramidal neurons during post-tetanic rhythmic activity and suggest that the following factors are responsible for post-tetanic oscillations. (1) Repetitive stimulation promotes a massive release of GABA from inhibitory neurons. (2) Early hyperpolarizing potentials evoked by the stimuli are followed by a slow GABA-mediated depolarization. (3) The slow depolarization (accompanied by a large drop in input resistance) induces repetitive firing in pyramidal neurons, at frequencies determined by their intrinsic properties. (4) Field effects synchronize this firing activity, converting individual cellular responses into rhythmic population spikes. The recent report that tetanically induced GABAergic depolarization of CA1 pyramidal neurons is accompanied by a large reduction in the extracellular space (Autere et al., 1999) suggests that field effects would be enhanced during post-tetanic oscillations.

\section{Comparison with other models}

Our new model for post-tetanic oscillations contrasts with an established model in which synchronization results from simultaneous recovery from large IPSPs experienced by principal neurons and interneurons excited by mGluR activation (Traub et al., 1996b; Whittington et al., 1997a). The variability of IPSP kinetics would complicate this process. They vary within individual cells, within individual cell types, and between different cell types (Pearce, 1993; Buhl et al., 1994, 1995; Ouardouz and Lacaille, 1997; Hajos and Mody, 1997; Banks et al., 1998). Differences between IPSP kinetics in pyramidal cells and interneurons may contribute to the much smaller cycle period variability of posttetanic $\gamma$ as compared to "interneuronal network $\gamma$ ", where pyramidal cells do not fire (Whittington et al., 1995; Traub et al., 1996a). Experiments in which evoked IPSPs were used to interrupt firing activity of principal neurons, showed a large temporal scattering for the rebound spikes, even in individual cells with the presynaptic event under complete control (Cobb et al., 1995). Our results indicate that field effects, rather than recovery from IPSPs, synchronize the population spikes characteristic of post-tetanic oscillations and account for the genesis of the regular rhythm and massive discharge of principal neurons during each cycle. IPSP kinetics (Buhl et al., 1995; Banks et al., 1998) are too slow to account for the fast $(70-100 \mathrm{~Hz})$ phase of the oscillation; rapid firing of neurons driven by strong depolarization, and synchronized by field effect, provide a novel, convincing mechanism.

\section{Physiological considerations}

In both neocortex and hippocampus the extracellular signal generated by $\gamma$ activity is small (Buzsáki, 1986; Suzuki and Smith, 1987; Singer and Gray, 1995; Bragin et al., 1995; Chrobak and Buzsáki, 1998; Penttonen et al., 1998). In marked contrast, the population spikes characteristic of tetanically evoked $\gamma$ are large and represent highly synchronous activity in the majority of the pyramidal cells. This last observation prompted Buzsáki and colleagues to describe post-tetanic $\gamma$ as "stimulation-induced afterdischarges" (Penttonen et al., 1998). Post-tetanic $\gamma$ may well turn out to have more to do with epilepsy than with cognition. However, it is important to acknowledge that the insights gained by modeling post-tetanic $\gamma$ provides a framework for developing analyses of other forms of $\gamma$ oscillation that more closely resemble $\gamma$ in vivo (Buhl et al., 1998; Fisahn et al., 1998).

\section{REFERENCES}

Alger BE, Nicoll RA (1979) GABA-mediated biphasic inhibitory responses in hippocampus. Nature 281:315-317.

Autere AM, Lamsa K, Kaila K, Taira T (1999) Synaptic activation of $\mathrm{GABA}_{\mathrm{A}}$ receptors induces neuronal uptake of $\mathrm{Ca}^{2+}$ in adult rat hippocampal slices. J Neurophysiol 81:811-816.

Ballyk BA, Quackenbush SJ, Andrew RD (1991) Osmotic effects on the CA1 neuronal population in hippocampal slices with special reference to glucose. J Neurophysiol 65:1055-1066.

Banks MI, Li TB, Pearce RA (1998) The synaptic basis of GABA A,slow. J Neurosci 18:1305-1317.

Blasco-Ibanez JM, Freund TF (1995) Synaptic input of horizontal interneurons in stratum oriens of the hippocampal CA1 subfield: structural basis of feed-back activation. Eur J Neurosci 7:2170-2180.

Bragin A, Jandó G, Nádasdy Z, Hetke J, Wise K, Buzsáki G (1995) $\gamma$ $(40-100 \mathrm{~Hz})$ oscillation in the hippocampus of the behaving rat. J Neurosci 15:47-60.

Buhl EH, Halasy K, Somogyi P (1994) Hippocampal unitary inhibitory postsynaptic potentials: diverse sources and number of synaptic release sites. Nature 368:823-828.

Buhl EH, Cobb SR, Halasy K, Somogyi P (1995) Properties of unitary IPSPs evoked by anatomically identified basket cells in the rat hippocampus. Eur J Neurosci 7:1989-2004.

Buhl EH, Tamas G, Fisahn A (1998) Cholinergic activation and tonic excitation induce persistent $\gamma$ oscillations in mouse somatosensory cortex in vitro. J Physiol (Lond) 513:117-126.

Burchell TR, Faulkner HJ, Whittington MA (1998) $\gamma$ frequency oscillations gate temporally coded afferent inputs in the rat hippocampal slice. Neurosci Lett 255:151-154.

Buzsáki G (1986) Hippocampal sharp waves: their origin and significance. Brain Res 398:242-252.

Buzsáki G, Chrobak JJ (1995) Temporal structure in spatially organized neuronal ensembles: a role for interneuronal networks. Curr Opin Neurobiol 5:504-510.

Cherubini E, Gaiarsa JL, Ben-Ari Y (1991) GABA: An excitatory transmitter in early postnatal life. Trends Neurosci 14:515-519.

Chrobak JJ, Buzsáki G (1998) $\gamma$ oscillations in the entorhinal cortex of the freely behaving rat. J Neurosci 18:388-398.

Cobb SR, Buhl EH, Halasy K, Paulsen O, Somogyi P (1995) Synchro- 
nization of neuronal activity in hippocampus by individual GABAergic interneurons. Nature 378:75-78.

Davies CH, Collingridge GL (1993) The physiological regulation of synaptic inhibition by $\mathrm{GABA}_{\mathrm{B}}$ autoreceptors in rat hippocampus. J Physiol (Lond) 472:245-265.

Davies CH, Davies SN, Collingridge GL (1990) Paired-pulse depression of monosynaptic GABA-mediated inhibitory postsynaptic responses in rat hippocampus. J Physiol (Lond) 424:513-531.

Davies CH, Clarke VR, Jane DE, Collingridge GL (1995) Pharmacology of postsynaptic metabotropic glutamate receptors in rat hippocampal CA1 pyramidal neurones. Br J Pharmacol 116:1859-1869.

Faber DS, Korn H (1989) Electrical field effects: their relevance in central neural networks. Physiol Rev 69:821-863.

Faulkner HJ, Traub RD, Whittington MA (1998) Disruption of synchronous $\gamma$ oscillations in the rat hippocampal slice: a common mechanism of anaesthetic drug action. Br J Pharmacol 125:483-492.

Fisahn A, Pike FG, Buhl EH, Paulsen O (1998) Cholinergic induction of network oscillations at $40 \mathrm{~Hz}$ in the hippocampus in vitro. Nature 394:186-189.

Grover LM, Lambert NA, Schwartzkroin PA, Teyler TJ (1993) Role of $\mathrm{HCO}_{3}{ }^{-}$ions in depolarizing $\mathrm{GABA}_{\mathrm{A}}$ receptor-mediated responses in pyramidal cells of rat hippocampus. J Neurophysiol 69:1541-1555.

Haas HL, Jefferys JGR (1984) Low-calcium field burst discharges of CA1 pyramidal neurones in rat hippocampal slices. J Physiol (Lond) 354:185-201.

Hajos N, Mody I (1997) Synaptic communication among hippocampal interneurons: properties of spontaneous IPSCs in morphologically identified cells. J Neurosci 17:8427-8442.

Jefferys JGR (1995) Non-synaptic modulation of neuronal activity in the brain: electric currents and extracellular ions. Physiol Rev 75:689-723.

Kaila K, Lamsa K, Smirnov S, Taira T, Voipio J (1997) Long-lasting GABA-mediated depolarization evoked by high-frequency stimulation in pyramidal neurons of rat hippocampal slice is attributable to a network-driven, bicarbonate-dependent $\mathrm{K}^{+}$transient. J Neurosci 17:7662-7672.

Lambert NA, Wilson WA (1994) Temporally distinct mechanisms of use-dependent depression at inhibitory synapses in the rat hippocampus in vitro. J Neurophysiol 72:121-130.

McBain CJ, DiChiara TJ, Kauer JA (1994) Activation of metabotropic glutamate receptors differentially affects two classes of hippocampal interneurons and potentiates excitatory synaptic transmission. J Neurosci 14:4433-4445.

Ouardouz M, Lacaille JC (1997) Properties of unitary IPSCs in hippocampal pyramidal cells originating from different types of interneurons in young rats. J Neurophysiol 77:1939-1949.

Pearce RA (1993) Physiological evidence for two distinct $\mathrm{GABA}_{\mathrm{A}}$ responses in rat hippocampus. Neuron 10:189-200.
Penttonen M, Kamondi A, Acsady L, Buzsáki G (1998) $\gamma$ frequency oscillation in the hippocampus of the rat: intracellular analysis in vivo. Eur J Neurosci 10:718-728.

Singer W, Gray CM (1995) Visual feature integration and the temporal correlation hypothesis. Annu Rev Neurosci 18:555-586.

Staley KJ, Soldo BL, Proctor WR (1995) Ionic mechanisms of neuronal excitation by inhibitory GABA $_{\mathrm{A}}$ receptors. Science 269:977-981.

Suzuki SS, Smith GK (1987) Spontaneous EEG spikes in the normal hippocampus. I. Behavioral correlates, laminar profiles and bilateral synchrony. Electroencephalogr Clin Neurophysiol 67:348-359.

Taira T, Lamsa K, Kaila K (1997) Posttetanic excitation mediated by $\mathrm{GABA}_{\mathrm{A}}$ receptors in rat CA1 pyramidal neurons. J Neurophysiol 77:2213-2218.

Taylor CP, Dudek FE (1984a) Excitation of hippocampal pyramidal cells by an electrical field effect. J Neurophysiol 52:126-142.

Taylor CP, Dudek FE (1984b) Synchronization without active chemical synapses during hippocampal afterdischarges. J Neurophysiol 52:143-155.

Traub RD, Dudek FE, Taylor CP, Knowles WD (1985) Simulation of hippocampal afterdischarges synchronized by electrical interactions. Neuroscience 14:1033-1038.

Traub RD, Whittington MA, Colling SB, Buzsáki G, Jefferys JGR (1996a) Analysis of $\gamma$ rhythms in the rat hippocampus in vitro and in vivo. J Physiol (Lond) 493:471-484.

Traub RD, Whittington MA, Stanford IM, Jefferys JGR (1996b) A mechanism for generation of long-range synchronous fast oscillations in the cortex. Nature 382:621-624.

Traub RD, Whittington MA, Buhl E, Jefferys JGR, Faulkner HJ (1999) On the mechanism of the $\gamma->\beta$ shift in neuronal oscillations induced in rat hippocampal slices by tetanic stimulation. J Neurosci 19:1088-1105.

Traynelis SF, Dingledine R (1989) Role of extracellular space in hyperosmotic suppression of potassium-induced electrographic seizures. J Neurophysiol 61:927-938.

Whittington MA, Jefferys JGR, Traub RD (1996) Effects of intravenous anaesthetic agents on fast inhibitory oscillations in the rat hippocampus in vitro. Br J Pharmacol 118:1977-1986.

Whittington MA, Traub RD, Jefferys JGR (1995) Synchronized oscillations in interneuron networks driven by metabotropic glutamate receptor activation. Nature 373:612-615.

Whittington MA, Stanford IM, Colling SB, Jefferys JGR, Traub RD (1997a) Spatiotemporal patterns of $\gamma$-frequency oscillations tetanically induced in the rat hippocampal slice. J Physiol (Lond) 502:591-607.

Whittington MA, Traub RD, Faulkner HJ, Stanford IM, Jefferys JGR (1997b) Recurrent EPSPs induced by synchronized fast cortical oscillations. Proc Natl Acad Sci USA 94:12198-12203. 